\title{
Crust or mantle? That is not the question, better unmix your granites
}

\author{
OSCAR LAURENT
}

CNRS-Géosciences Environnement Toulouse

Presenting Author: oscar.laurent@Get.omp.eu

The question of the crustal or mantle origin of granite predates the validation of the plate tectonics theory, yet is still a matter of debates in the community. This issue pertains to the rates and mechanisms of continental crust formation through time, as mantle-derived granite results in an addition to the continental volume, whereas crust-derived granite only redistributes the mass within the crust. In fact, this is not a binary question, as crust and mantle melting occur together in several, if not most geodynamic settings. Many granitoid types or associations in these settings are therefore hybrids. Unmixing the various proportions of mantle and crustal components at all spatial-temporal scales is then key to address the balance between crustal growth and reworking through time.

This question has long been addressed using conventional radiogenic $(\mathrm{Sr}, \mathrm{Nd}, \mathrm{Hf}$ and $\mathrm{Pb}$ ) isotopes as proxies of granite petrogenesis. However, the geochemical affinity of these isotope systems makes them over-sensitive to the involvement of the crust in any hybrid system. In addition, hybridization can take place at all levels along magma pathways from mantle/lower crust to upper crust/surface, which may result in strongly different interpretations of a given isotopic composition in terms of crust vs. mantle balance, yet is not resolvable considering only the end-products (granites). These problems have been progressively overlooked, which combined to the recent use of radiogenic isotopes as global proxies of granite petrogenesis (e.g. the zircon Hf isotopic record), led to systematic biases and misinterpretations.

Potential ways forward include the combination of observations at all levels in the lithosphere, from mantle and lower crustal source regions, to magma transfer and accumulation zones in the mid-/upper crust and eruption at the surface, to re-integrate the bulk mass balance between mantle and crust at the scale of an entire, transcrustal magmatic system. Such local integrative approach is particularly promising when coupled with tools that would eventually help up-scaling observations to a global scale, including forward, predictive numerical modelling (geochemical, thermal, thermodynamic) of crust / mantle interactions ; and novel geochemical tracers such as trace elements in accessory minerals and non-conventional isotopic systems. 